\title{
Status of terrestrial mammals at the Kafue-Zambezi interface: implications for transboundary connectivity
}

\author{
Robin Lines, Joseph Tzanopoulos and Douglas MacMillan
}

\begin{abstract}
The Kavango-Zambezi Transfrontier Conservation Area Programme promotes landscape-level connectivity between clusters of wildlife management areas in five neighbouring countries. However, declining regional biodiversity can undermine efforts to maintain, expand and link wildlife populations. Narratives promoting species connectivity should thus be founded on studies of system and state changes in key resources. By integrating and augmenting multiple data sources throughout eight wildlife management areas, covering 1.7 million ha, we report changes during 1978-2015 in the occurrence and distribution of 31 mammal species throughout a landscape linking the Greater Kafue System to adjacent wildlife management areas in Namibia and Botswana. Results indicate species diversity is largely unchanged in Kafue National Park and Mulobezi and Sichifulo Game Management Areas. However, 100\% of large carnivore and $64 \%$ of prey diversity have been lost in the Simalaha areas, and there is no evidence of migrational behaviour or species recolonization from adjacent wildlife areas. Although temporal sampling scales influence the definition of species occupancy and distribution, and data cannot elucidate population size or trends, our findings indicate an emerging connectivity bottleneck within Simalaha. Evidence suggests that at current disturbance levels the Greater Kafue System, Zambia's majority component in the Kavango-Zambezi Transfrontier Conservation Area, is becoming increasingly isolated at the trophic scale of large mammals. Further investigations of the site-specific, interacting drivers influencing wildlife distribution and occurrence are required to inform appropriate conservation interventions for wildlife recovery in key areas identified to promote transboundary connectivity in the KavangoZambezi Transfrontier Conservation Area.
\end{abstract}

Keywords Connectivity, Kafue, Kavango-Zambezi Transfrontier Area, mammal loss, transboundary conservation, wildlife management area

Robin Lines (Corresponding author), Joseph TZANopoulos and Douglas MacMillan Durrell Institute of Conservation and Ecology, Marlow Building, The University of Kent, Canterbury, Kent, CT2 7NR, UK

E-mail r1291@kent.ac.uk

Received 7 February 2017. Revision requested 8 June 2017.

Accepted 13 October 2017. First published online 16 May 2018.

\section{Introduction}

Wildlife management areas are frequently clustered along international borders, with ecosystems divided by arbitrarily drawn political boundaries (Zbicz, 1999; Hanks, 200o). Where fences and physical barriers are combined with expanding human settlements and intensifying agro-pastoralist activities, overexploitation and decline of wildlife populations can occur (Ogutu et al., 2016). Additionally, invasion, disease, pollution and climate change (Pachauri et al., 2014; Maxwell et al., 2016) interact with intrinsic species traits (Cardillo et al., 2008) to inhibit or sever wildlife movement patterns, isolating core wildlife management areas (Margules \& Pressey, 2000; Newmark, 2008). Together these drivers are exposing wildlife populations to escalating edge-effects and ecological traps, threatening species persistence within and outside protected areas (Woodroffe \& Ginsberg, 1998; Battin, 2004).

Conversely, intact species assemblages have wide-ranging implications for sustainable and resilient social-ecological systems (Cumming, 2011). Heterogeneity and functional diversity drive productivity and a system's capacity to absorb, resist and respond to shocks, perturbations and other stressors that negatively affect its structure and function (Fischer et al., 2006). Cumulatively, threats to species persistence undermine habitat integrity, ecosystem services, food security, the development of sustainable wildlife-based land uses and human well-being (Millennium Ecosystem Assessment, 2005; Lindsey et al., 2013b).

Acknowledging the limitations imposed by these constraints, stakeholders in southern Africa are increasingly embracing Transfrontier Conservation Areas as a new conservation paradigm (Hanks, 200o), considered to be an evolution of previous community-based natural resource management approaches that yielded mixed results (Andersson, 2017). Enticing narratives include the integration of biodiversity conservation with the promotion of sustainable socio-economic development and a culture of peace and cooperation at the ecosystem level, linked to the removal of fences and other barriers inhibiting the free movement of wildlife across vast interconnected landscapes (van der Linde et al., 2001; Hanks, 2003).

The Kavango-Zambezi Transfrontier Conservation Area is intended to capitalize on the region's unique diversity and distribution of wildlife assets by advocating shared natural resource management and development goals across a 
network of protected areas spanning $>500,000 \mathrm{~km}^{2}$ at the interface of Angola, Botswana, Namibia, Zambia and Zimbabwe (KAZA TFCA Secretariat, 2011b; Hanks \& Myburgh, 2015). Stated objectives to integrate conservation and development, promote peace and cooperation, and facilitate connectivity of wildlife populations between clusters of wildlife management areas have become popular and compelling programme narratives driving north-south finance initiatives, NGO engagement, and state buy-in (PPF, 2008; KAZA TFCA Secretariat, 2011a; WWF, 2011).

Notwithstanding evolving conservation and development narratives, the success of the Kavango-Zambezi Transfrontier Conservation Area Programme is constrained by many existing and emerging challenges. Mounting anthropogenic pressures combined with poor land-use planning, institutional conflicts and stakeholder disenfranchisement (Andersson, 2017) are driving encroachment into wildlife areas, habitat loss and fragmentation (Newmark, 2008; Simukonda, 2008; Watson et al., 2015), and unsustainable harvesting of wildlife, threatening many of the Conservation Area's iconic natural assets (Lindsey et al., 2013a). With the region's human population expected to double by 2050 (United Nations, Department of Economic and Social Affairs, Population Division, 2015) and likely impacts of climate change exacerbating challenges to socio-economic development (Bellard et al., 2012; Pachauri et al., 2014), even moderately optimistic scenarios imply regional biodiversity loss will accelerate significantly this century (Biggs et al., 2008).

Collectively these challenges raise important questions about the scope, scale and ambition of narratives promoting landscape-level linkages, the interventions required to maintain or expand connectivity, and the purposes these proposed linkages may serve in the long term (Cumming, 2008). There is thus a clear imperative to promote evidencebased socio-economic and environmental policies and interventions built around the application of conservation science (Sutherland et al., 2004), including research and monitoring of changes in the state of sites and systems, and their response to factors driving connectivity at the scale of interest. The process of informed decision-making is data hungry, and local, regional and transboundary data sources are disparate and inconsistent, undermining attempts to understand complex social-ecological systems such as the Kavango-Zambezi Transfrontier Conservation Area. Data deficiencies ultimately constrain effective decision-making and appropriate interventions to promote biodiversity conservation and development.

Here we interrogate and synthesize existing data sources, and supplement them with additional research to document the historical and contemporary status of the African elephant Loxodonta africana, five large carnivores, one mesopredator and 24 prey species throughout eight wildlife management areas between the Greater Kafue System and the Zambezi River. This landscape is promoted as a key linkage to the central cluster of wildlife management areas in Namibia and Botswana, at the heart of the KavangoZambezi Transfrontier Conservation Area (KAZA TFCA Secretariat, 2014). Through integration, harmonization and triangulation of data we were able to determine changes in species occurrence and distribution by wildlife management area and designation.

\section{Study area}

The boundaries of the Kavango-Zambezi Transfrontier Conservation Area are imprecise (Andersson, 2017) but Cumming (2008) characterized the area as comprising a matrix of $>70$ wildlife management areas, from National Parks under strict state control to multiple-use areas under community management. These wildlife management areas are grouped into three major clusters and five periphery sub-clusters, with Kafue National Park and surrounding wildlife management areas constituting the major northern cluster (Fig. 1).

Kafue National Park $\left(22,400 \mathrm{~km}^{2}\right)$ is Zambia's oldest and largest protected area, the largest National Park in the Kavango-Zambezi Transfrontier Conservation Area and the second largest National Park in Africa (UNEP/WCMC, 2016). Together with nine surrounding IUCN category VI Game Management Areas and multiple Forest Reserves, the effective unfenced wildlife management area, referred to as the Greater Kafue Landscape or System, covers $68,000 \mathrm{~km}^{2}$ and includes $9 \%$ of Zambia's land mass and $>13 \%$ of the KavangoZambezi Transfrontier Conservation Area estate (Moss, 2012).

Most of the Greater Kafue System lies at 900-1,100 m altitude. Mean annual rainfall is $650 \mathrm{~mm}$ in the south and $1,050 \mathrm{~mm}$ in the north, falling predominantly during November-April. Vegetation is characterized by the Zambezian Miombo Woodland ecoregion, typical of large areas throughout southern and eastern Africa, dominated by Brachystegia spp., Combretum spp., Mopane spp., Terminalia spp. and Baikaea spp. Woodlands are interspersed with open floodplain grasslands and dambos (ZAWA, 2010). Species records include 158 mammals, 481 birds, 69 reptiles, 35 amphibians and 58 fish, with the greatest diversity of antelopes in Africa ( 21 species), an intact carnivore guild and a full complement of Zambia's large mammals, with the exception of the giraffe Giraffa giraffa, black rhinoceros Diceros bicornis and tsessebe Damaliscus lunatus (Moss, 2012).

The Greater Kafue System is Zambia's majority component within the Kavango-Zambezi Transfrontier Conservation Area (KAZA TFCA Secretariat, 2014), with connectivity to the broader Kavango-Zambezi landscape contingent on the maintenance of a landscape-level linkage routing south-southwest through a mosaic of nominally, potentially and possibly 


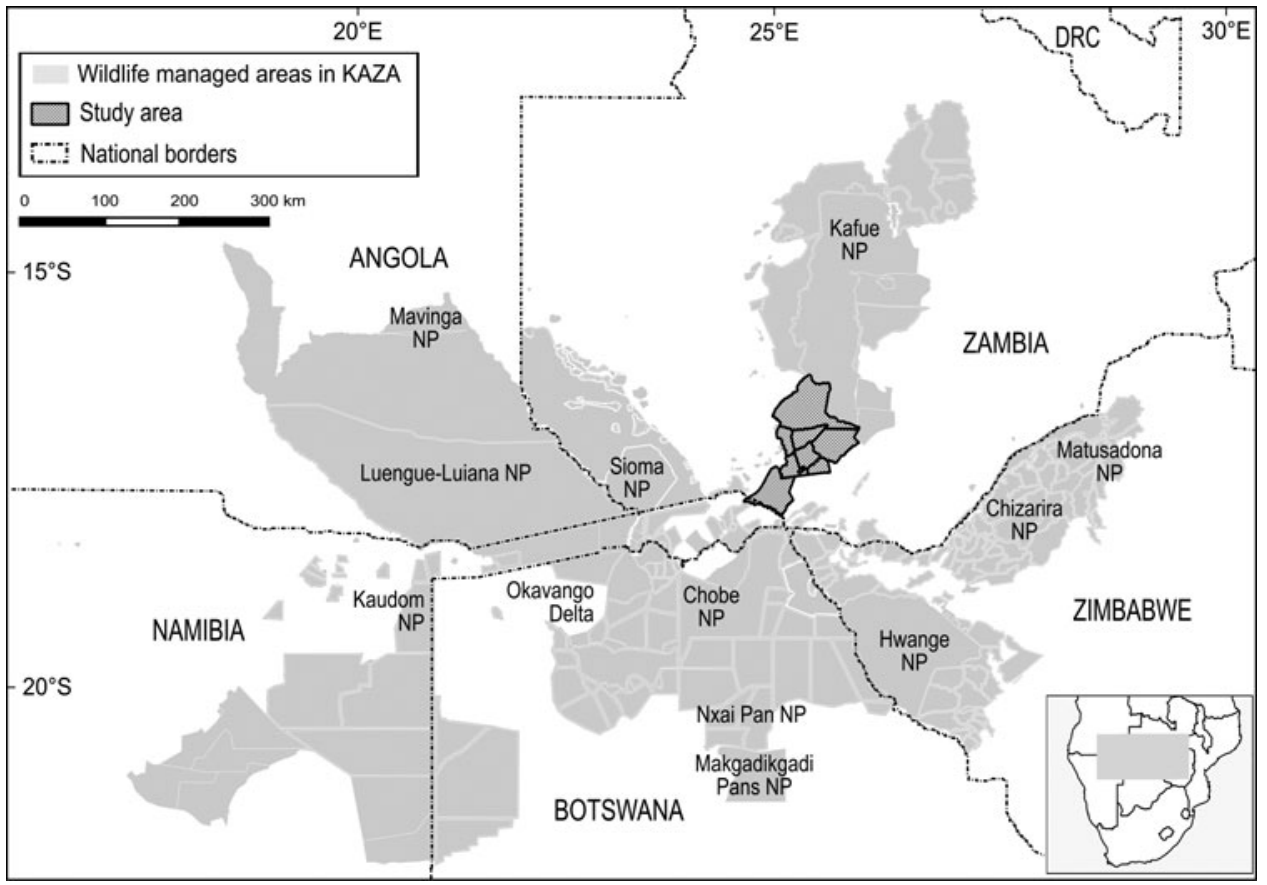

FIG. 1 Clusters of wildlife management areas in the Kavango-Zambezi Transfrontier Conservation Area landscape in southern Africa (adapted from KAZA TFCA Secretariat, 2014; PPF, 2008). protected wildlife management areas, including Mulobezi and Sichifulo Game Management Areas, Nachitwe, Martin and Machili Forest Reserves, the Nyawa communal areas, and the Simalaha Communal Conservancy, proclaimed in 2011 (Fig. 2). Together these wildlife management areas extend the Greater Kafue System to c. 7.3 million ha.

A secondary (south-westerly) linkage passing through Mulobezi to Sioma National Park (bordering Namibia and Angola) has been proposed, although our focus is on the linkage that broadly follows the Machili stream catchment basin from the border of Kafue National Park to the northern bank of the Zambezi River, adjacent to Kasika and Salambala Communal Conservancies of the eastern Zambezi region in Namibia, and through to Chobe National Park in Botswana.

The proposed landscape linkage is $140-170 \mathrm{~km}$. The human population is c. 110,000 and increasing by $2.5 \%$ annually, with a population density of c. 4 people per $\mathrm{km}^{2}$ (CSO, 2010). Communities are centred on a few larger settlements of 5,000-10,000 residents, and otherwise in clusters of scattered villages typically concentrated along water courses, seasonal waterholes and a few pumped groundwater supplies. Subsistence agro-pastoralists dominate this landscape, with residents largely dependent on exploiting a wide range of natural resources to meet their basic livelihood needs (Musgrave, 2016). Formal employment opportunities beyond a few distant urban settlements are negligible. Customary law within the Lozi, Nkoya and Tonga ethnolinguistic groups constitutes the de facto regional governance system (Brelsford, 1965; Musgrave, 2016).

Biodiversity conservation budgets have varied significantly throughout this landscape, both spatially and temporally. Although precise figures are unavailable, sources indicate that Kafue National Park (operating with only $10-15 \%$ of recommended protected area budgets) has received the greatest level of long-term support for biodiversity conservation throughout the study area, followed by Mulobezi and then Sichifulo Game Management Areas, which receive minor budget allocations from the State Wildlife Authority, augmented by finance and in-kind operational support from resident safari hunting operators and conservation NGOs. Nachitwe, Martin and Machili Forest Reserves have received minor budgets intermittently from the State Wildlife Authority and Forestry Department (ZAWA, 2010; C. Chifunte, pers. comm. 2015.). The Simalaha Communal Conservancy started receiving formal wildlife resource protection as recently as 2013, having had no formal biodiversity conservation budgets since before 1978 (HRH Chief Inyambo Yeta, pers. comm. 2015). We were unable to ascertain if the Nyawa communal areas receive any formal wildlife management budget. In addition, a 24,000 ha fenced Wildlife Recovery Sanctuary to the south of Simalaha, with an extensive open border along the Zambezi River, has received $>600$ head of game of eight species since 2013: a significant investment promoted as a justification for restocking the broader Simalaha Communal Conservancy (PPF, 2015).

\section{Methods}

\section{Data sources}

The earliest records of occurrence and distribution of terrestrial mammals in the vicinity of the proposed 


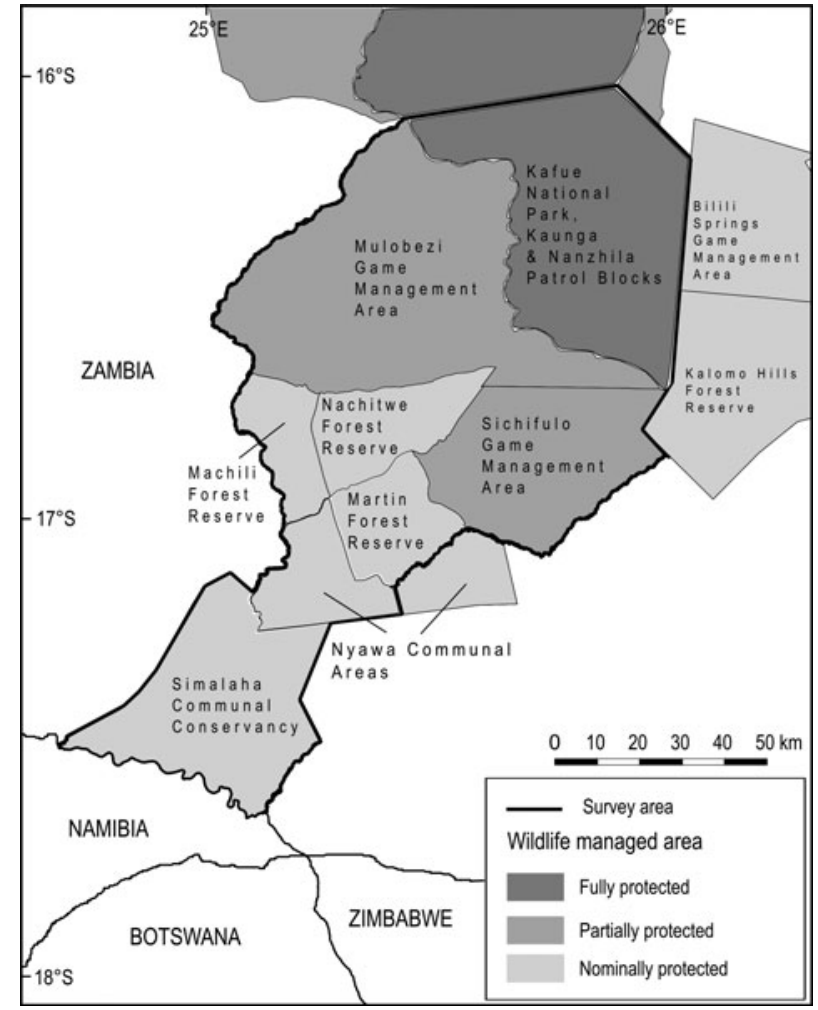

FIG. 2 Wildlife management areas within the study area.

Kafue-Zambezi linkage are limited to disparate notes and reports in the grey literature from early explorers, hunters, traders and missionaries, dating back to the late 19th century (e.g. Sampson, 1972; Holub, 1975), with approximate location data variously reported in relation to key landscape features. The first published checklists for Zambia (Pitman, 1934; Lancaster, 1953; Ansell, 1957, 1959, 1960) indicate there were no changes to the assemblage of large mammals in and around Kafue National Park prior to the extirpation of the black rhinoceros in the mid 1980s, although there are unresolved questions regarding anecdotal records of a relic giraffe population (P. Moss, pers. comm. 2015). Data for these checklists were collected ostensibly through ad hoc and opportunistic sightings by government staff and expert observers reporting from their travels throughout the country, augmented by trading records and hunting ledgers kept by District Commissioners.

The first systematic collation of species occurrence and distribution data was published by Ansell (1978), superseding previous literature. Amalgamated checklist data were mapped within quarter-degree grid squares, based on 1:50,000 Ordnance Survey map sheets. Given the absence of reports from many inaccessible and largely unmapped periphery areas, the data reflect minimum regional species ranges; nonetheless, much of the study area can be considered to be well mapped because of the established network of access routes developed alongside the nascent teak logging and safari hunting industries (Musgrave, 2016).

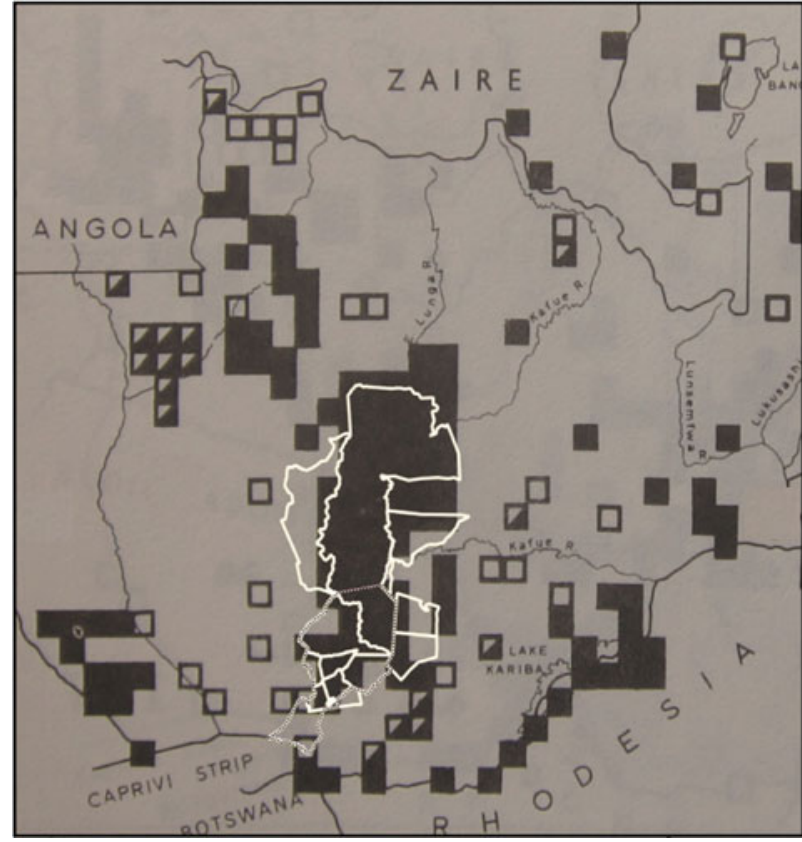

FIG. 3 Boundaries of contemporary wildlife management areas (in white) and the study area (dotted line) projected onto Ansell's (1978) map of the known (filled squares), possible (half-filled squares) and former range (unfilled squares) of the blue wildebeest Connochaetes taurinus.

Ansell (1978) reported on 38 terrestrial mammals $>10 \mathrm{~kg}$ in weight, from 11 families, but we restricted the contemporary list to 31 readily detected species from nine families, omitting seven species considered to be at the edge of their known range and/or habitat specialists requiring species-specific survey techniques beyond the scope of this study.

Boundaries of contemporary land-use classifications (UNEP-WCMC, 2016) were projected over Ansell's (1978) maps using QGIS (QGIS Development Team, 2016; Fig. 3), to facilitate extraction of historical species distribution data at comparable spatial scales, for Kafue National Park (Kaunga and Nanzhila management blocks, 570,000 ha), Mulobezi Game Management Area (hereafter Mulobezi, 342,000 ha), Sichifulo Game Management Area, including Nachitwe, Martin and Machili Forest Reserves (hereafter Sichifulo, 409,000 ha), and the Nyawa/Simalaha areas (c. 280,000 ha).

In compiling contemporary data sets (Fig. 4) we constrained data gathering to three broadly comparable ground-based survey approaches. We omitted aerial survey data (e.g. DNPW, 2016) because of limitations to detection rates for many species of primary interest in forested areas (Jachmann, 2002).

Firstly, the resident safari hunting operator, operational throughout Mulobezi and Sichifulo during the preceding decade, was asked to provide sighting reports for 31 terrestrial mammals of interest through a questionnaire survey following the 2014 hunting season. Multiple groups of 


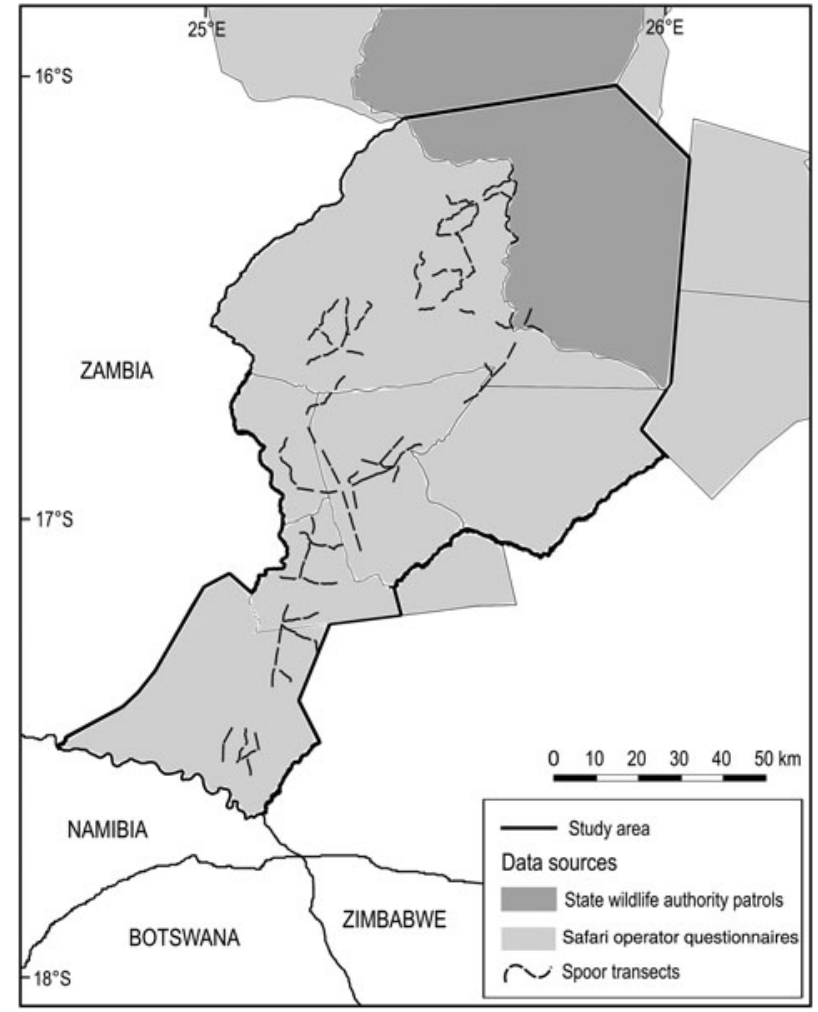

FIG. 4 Sources of data within the study area for contemporary analyses of terrestrial mammals at the Kafue-Zambezi interface (Fig. 1).

guides, hunters and skilled trackers traverse both Mulobezi and Sichifulo on and off road, covering $>10,000 \mathrm{~km}$ each dry season (R. Kraljic, pers. comm. 2014). This was considered to amount to sufficient survey effort and expertise to detect target species.

Secondly we collected patrol data from the local State and Community Wildlife Police Officers responsible for wildlife protection in southern Kafue National Park, Mulobezi and Sichifulo. We amalgamated data for the Kafue patrol blocks adjacent to Mulobezi and Sichifulo to cover a single area including the border area north of both Mulobezi and Sichifulo Game Management Areas. These data comprised 1,920 georeferenced wildlife sightings from 46,170 man-days of foot patrols during 2014-2015 (ZAWA, unpubl. data).

In 2015 we undertook a systematic randomized spoor and sightings survey of large carnivores and their principal prey throughout $10400-\mathrm{km}^{2}$ survey blocks in Mulobezi, Sichifulo and the Nyawa/Simalaha areas. Detection probability and survey effort were optimized for large carnivores following Funston et al. (2010) and Thorn et al. (2010). In addition, a site-specific calibration process was undertaken during July-September 2014, conducted at various spatio-temporal scales, to establish the survey effort required to detect large carnivores and sample the landscape in a single season (MacKenzie \& Royle, 2005; D.I. MacKenzie, pers. comm. 2015). In total, $1024-\mathrm{km}$ transects were surveyed on foot three times by RL and two experienced local trackers from the safari hunting industry, amounting to $1,224 \mathrm{~km}$ of spoor transects during the dry season of May-October 2015.

\section{Data analysis}

A confirmed sighting from any of the three selected expert contemporary sources was considered to be sufficient to detect species presence at the scale of interest. Given the atypical nature of ongoing ungulate reintroductions and management in the fenced Simalaha Wildlife Sanctuary, we restrict reporting to the detection of the carnivore guild for this subset of the Simalaha Communal Conservancy.

Data for each of the four composite wildlife management area blocks, from the three data sources, were compiled against historical data to determine if any changes in species occurrence and distribution had occurred. Outputs reflected species persistence, loss or colonization at the composite wildlife management area scale.

As survey methods were optimized for resident large carnivores and their principal prey species, the risk of nondetection was elevated for species that exhibited significant seasonal (migration) or non-resident (emigration and immigration) movement patterns, or where surveys did not cover the restricted ranges of habitat specialists. These constraints are acknowledged in Table 1 and subsequent analyses.

An amalgamated distribution map was generated for the five extant large carnivores, indicating their historical range within the survey area, and current known range within studied wildlife management areas.

\section{Results}

Table 1 indicates few non-detections recorded against any data sources since 1978 throughout southern Kafue National Park, Mulobezi or Sichifulo. However, the hippopotamus Hippopotamus amphibius appears to be no longer resident in any of the waterways along the Machili stream and catchment area, and the klipspringer Oreotragus oreotragus appears to be absent from Mulobezi, although core habitat for this species went unsurveyed. The steenbok Raphicerus campestris is considered to be at the extent of its north-east range approaching Kafue National Park, with a single sighting recorded in Mulobezi.

The absence of confirmed sightings of the caracal Caracal caracal and serval Leptailurus serval by Wildlife Police Officer patrols in southern Kafue National Park appear to be an anomaly, given detections of the species in adjacent Game Management Areas. Although it is likely this anomaly represents non-detection error versus absence, we discarded these species from the final checklist. 
TABLE 1 Species detected in various studies conducted in wildlife management areas at the Kafue-Zambezi interface (Fig. 1), their IUCN Red List status, and whether or not there was a change in distribution between 1978 and 2014-2015.

\begin{tabular}{|c|c|c|c|c|c|c|c|c|c|c|c|c|c|c|c|c|c|}
\hline \multirow[b]{2}{*}{ Species } & \multirow[b]{2}{*}{$\begin{array}{l}\text { Red List } \\
\text { status }^{1}\end{array}$} & \multicolumn{4}{|c|}{ Ansell (1978) } & \multicolumn{2}{|c|}{$\begin{array}{l}\text { R. Kraljik (unpubl. } \\
\text { data, 2013/2014) }\end{array}$} & \multicolumn{3}{|c|}{$\begin{array}{l}\text { Zambia Wildlife Authority } \\
\text { (unpubl. data, 2014/2015) }\end{array}$} & \multicolumn{3}{|c|}{ This study $(2014 / 2015)$} & \multicolumn{4}{|c|}{ Distribution change 1978-2014/2015 } \\
\hline & & $\begin{array}{l}\text { Kafue NP/ } \\
\text { South }\end{array}$ & Mulobezi & Sichifulo & Simalaha & Mulobezi & Sichifulo & $\begin{array}{l}\text { Kafue NP/ } \\
\text { South }\end{array}$ & Mulobezi & Sichifulo & Mulobezi & Sichifulo & Simalaha & $\begin{array}{l}\text { Kafue NP/ } \\
\text { South }\end{array}$ & Mulobezi & Sichifulo & Simalaha \\
\hline $\begin{array}{l}\text { Cheetah Acinonyx } \\
\text { jubatus }\end{array}$ & $\mathrm{VU}$ & $\checkmark$ & $\checkmark$ & $\checkmark$ & $\checkmark$ & $\checkmark$ & $\checkmark$ & $\checkmark$ & & & $\checkmark$ & $\checkmark$ & & No & No & No & Yes \\
\hline Lion Panthera leo & VU & $\checkmark$ & $\checkmark$ & $\checkmark$ & $\checkmark$ & $\checkmark$ & $\checkmark$ & $\checkmark$ & $\checkmark$ & $\checkmark$ & $\checkmark$ & $\checkmark$ & & No & No & No & $\mathrm{Yes}^{2}$ \\
\hline $\begin{array}{l}\text { Leopard Panthera } \\
\text { pardus }\end{array}$ & VU & $\checkmark$ & $\checkmark$ & $\checkmark$ & $\checkmark$ & $\checkmark$ & $\checkmark$ & $\checkmark$ & $\checkmark$ & $\checkmark$ & $\checkmark$ & $\checkmark$ & $\checkmark$ & No & No & No & Yes $^{2}$ \\
\hline $\begin{array}{l}\text { Spotted hyaena } \\
\text { Crocuta crocuta }\end{array}$ & $\mathrm{LC}$ & $\checkmark$ & $\checkmark$ & $\checkmark$ & $\checkmark$ & $\checkmark$ & $\checkmark$ & $\checkmark$ & $\checkmark$ & $\checkmark$ & $\checkmark$ & $\checkmark$ & & No & No & No & $\mathrm{Yes}^{2}$ \\
\hline $\begin{array}{l}\text { Side-striped jackal } \\
\text { Canis adustus }\end{array}$ & $\mathrm{LC}$ & $\checkmark$ & $\checkmark$ & $\checkmark$ & $\checkmark$ & $\checkmark$ & $\checkmark$ & $\checkmark$ & & & $\checkmark$ & $\checkmark$ & $\checkmark$ & No & No & No & No \\
\hline $\begin{array}{l}\text { African wild dog } \\
\text { Lycaon pictus }\end{array}$ & EN & $\checkmark$ & $\checkmark$ & $\checkmark$ & $\checkmark$ & $\checkmark$ & $\checkmark$ & $\checkmark$ & $\checkmark$ & $\checkmark$ & $\checkmark$ & $\checkmark$ & & No & No & No & Yes \\
\hline $\begin{array}{l}\text { African elephant } \\
\text { Loxodonta africana }\end{array}$ & VU & $\checkmark$ & $\checkmark$ & $\checkmark$ & $\checkmark$ & $\checkmark$ & $\checkmark$ & $\checkmark$ & $\checkmark$ & $\checkmark$ & $\checkmark$ & $\checkmark$ & & No & No & No & $\mathrm{Yes}^{2}$ \\
\hline $\begin{array}{l}\text { Burchell's zebra } \\
\text { Equus quagga }\end{array}$ & NT & $\checkmark$ & $\checkmark$ & $\checkmark$ & $\checkmark$ & $\checkmark$ & $\checkmark$ & $\checkmark$ & $\checkmark$ & $\checkmark$ & $\checkmark$ & $\checkmark$ & & No & No & No & $\mathrm{Yes}^{3}$ \\
\hline $\begin{array}{l}\text { Warthog Phacochoerus } \\
\text { africanus }\end{array}$ & $\mathrm{LC}$ & $\checkmark$ & $\checkmark$ & $\checkmark$ & $\checkmark$ & $\checkmark$ & $\checkmark$ & $\checkmark$ & $\checkmark$ & $\checkmark$ & $\checkmark$ & $\checkmark$ & & No & No & No & Yes \\
\hline $\begin{array}{l}\text { Bushpig Potamochoerus } \\
\text { larvatus }\end{array}$ & $\mathrm{LC}$ & $\checkmark$ & $\checkmark$ & $\checkmark$ & $\checkmark$ & $\checkmark$ & $\checkmark$ & $\checkmark$ & $\checkmark$ & $\checkmark$ & $\checkmark$ & $\checkmark$ & & No & No & No & Yes \\
\hline $\begin{array}{l}\text { Hippopotamus } \\
\text { Hippopotamus } \\
\text { amphibius }\end{array}$ & VU & $\checkmark$ & $\checkmark$ & $\checkmark$ & $\checkmark$ & & & $\checkmark$ & & & & & & No & $\mathrm{Yes}^{2}$ & $\mathrm{Yes}^{2}$ & $\mathrm{Yes}^{2}$ \\
\hline $\begin{array}{l}\text { Hartebeest Alcelaphus } \\
\text { lichtensteinii }\end{array}$ & LC & $\checkmark$ & $\checkmark$ & $\checkmark$ & $\checkmark$ & $\checkmark$ & $\checkmark$ & $\checkmark$ & $\checkmark$ & $\checkmark$ & $\checkmark$ & $\checkmark$ & & No & No & No & Yes \\
\hline $\begin{array}{l}\text { Blue wildebeest } \\
\text { Connochaetes taurinus }\end{array}$ & LC & $\checkmark$ & $\checkmark$ & $\checkmark$ & $\checkmark$ & $\checkmark$ & $\checkmark$ & $\checkmark$ & $\checkmark$ & $\checkmark$ & $\checkmark$ & $\checkmark$ & & No & No & No & $\mathrm{Yes}^{3}$ \\
\hline $\begin{array}{l}\text { Klipspringer Oreotragus } \\
\text { oreotragus }\end{array}$ & LC & $\checkmark$ & & $\checkmark$ & & $\checkmark$ & $\checkmark$ & $\checkmark$ & & & & & & No & No & No & No \\
\hline Oribi Ourebia ourebi & LC & $\checkmark$ & $\checkmark$ & $\checkmark$ & $\checkmark$ & $\checkmark$ & $\checkmark$ & $\checkmark$ & $\checkmark$ & $\checkmark$ & $\checkmark$ & $\checkmark$ & $\checkmark$ & No & No & No & No \\
\hline $\begin{array}{l}\text { Steenbok Raphicerus } \\
\text { campestris }\end{array}$ & $\mathrm{LC}$ & $\checkmark$ & $\checkmark$ & $\checkmark$ & $\checkmark$ & & & & & & $\checkmark$ & & & $\mathrm{UK}^{4}$ & No & Yes & Yes \\
\hline $\begin{array}{l}\text { Sharpe's grysbok } \\
\text { Raphicerus sharpei }\end{array}$ & LC & $\checkmark$ & $\checkmark$ & $\checkmark$ & $\checkmark$ & $\checkmark$ & $\checkmark$ & $\checkmark$ & $\checkmark$ & $\checkmark$ & $\checkmark$ & $\checkmark$ & $\checkmark$ & No & No & No & No \\
\hline $\begin{array}{l}\text { African buffalo } \\
\text { Syncerus caffer }\end{array}$ & LC & $\checkmark$ & $\checkmark$ & $\checkmark$ & $\checkmark$ & $\checkmark$ & $\checkmark$ & $\checkmark$ & $\checkmark$ & $\checkmark$ & $\checkmark$ & $\checkmark$ & & No & No & No & Yes \\
\hline $\begin{array}{l}\text { Common eland } \\
\text { Tragelaphus oryx }\end{array}$ & LC & $\checkmark$ & $\checkmark$ & $\checkmark$ & $\checkmark$ & $\checkmark$ & $\checkmark$ & $\checkmark$ & $\checkmark$ & $\checkmark$ & $\checkmark$ & & & No & No & No & Yes \\
\hline $\begin{array}{l}\text { Bushbuck Tragelaphus } \\
\text { scriptus }\end{array}$ & LC & $\checkmark$ & $\checkmark$ & $\checkmark$ & $\checkmark$ & $\checkmark$ & $\checkmark$ & $\checkmark$ & $\checkmark$ & $\checkmark$ & $\checkmark$ & $\checkmark$ & & No & No & No & Yes \\
\hline $\begin{array}{l}\text { Sitatunga Tragelaphus } \\
\text { spekii }\end{array}$ & $\mathrm{LC}$ & $\checkmark$ & & & & & & & & & & & & Yes & No & No & No \\
\hline $\begin{array}{l}\text { Greater kudu } \\
\text { Tragelaphus } \\
\text { strepsiceros }\end{array}$ & LC & $\checkmark$ & $\checkmark$ & $\checkmark$ & $\checkmark$ & $\checkmark$ & $\checkmark$ & $\checkmark$ & $\checkmark$ & $\checkmark$ & $\checkmark$ & $\checkmark$ & $\checkmark$ & No & No & No & No \\
\hline $\begin{array}{l}\text { Common duiker } \\
\text { Sylvicapra grimmia }\end{array}$ & LC & $\checkmark$ & $\checkmark$ & $\checkmark$ & $\checkmark$ & $\checkmark$ & $\checkmark$ & $\checkmark$ & $\checkmark$ & $\checkmark$ & $\checkmark$ & $\checkmark$ & $\checkmark$ & No & No & No & No \\
\hline
\end{tabular}




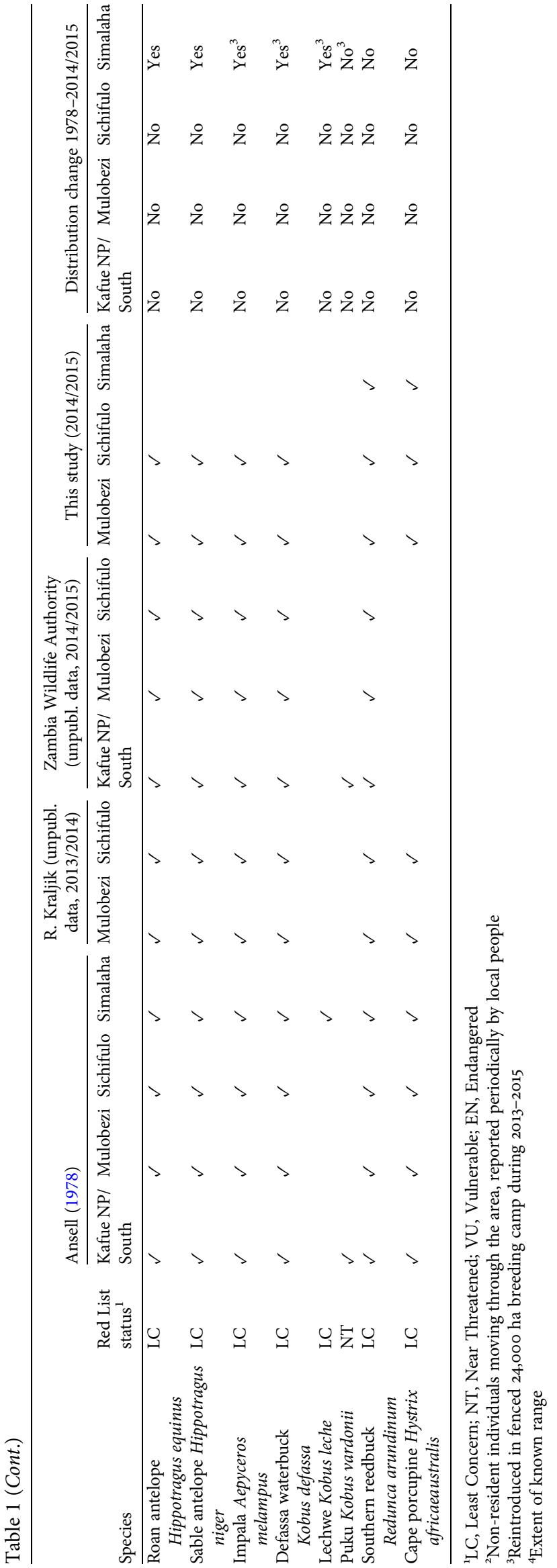

Significant losses have occurred in the Simalaha Communal Conservancy, where 21 of 31 terrestrial mammals were undetected (Fig. 5) and the side-striped jackal Canis adustus was the only widespread carnivore detected. The spotted hyaena Crocuta crocuta and the leopard Panthera pardus were the only large carnivores detected within $60 \mathrm{~km}$ of the Zambezi River in the Nyawa communal areas (Fig. 6). The remainder of the large carnivore guild appears to be extirpated from the Simalaha/Nyawa area, along with all ungulates $>20 \mathrm{~kg}$ except the southern reedbuck Redunca arundinum and the greater kudu Tragelaphus strepsiceros. Kudu were also the only herding ungulate to be detected in Simalaha, although no aggregations of more than three individuals were detected. Neither the warthog Phacochoerus africanus nor the bushpig Potamochoerus larvatus, both habitat and feeding generalists with high reproductive rates, were detected in Simalaha. Although $>600$ head of game, comprising seven species, have been introduced into the 24,000 ha Simalaha Wildlife Recovery Sanctuary since 2013, only the side-striped jackal was detected inside the (non-predator-proof) area. There was no evidence of any species range extension or recolonization throughout any of the sampled areas.

Although no long-term or landscape-level survey programme is in place for systematic monitoring of changes in species occurrence, distribution or abundance, much existing expertise and anecdotal evidence implies there have been large-scale population declines throughout the Greater Kafue System and beyond since 1978 (C. Chifunte, L. Daka, J. Hanks, HRH Chief Moomba, P. Moss \& HRH Chief Inyambo Yeta, pers. comms). Contemporary data indicate Kafue National Park, the region's prime wildlife area, is maintaining the majority of terrestrial mammals at significantly below carrying capacity (Simukonda, 2008). Nonetheless, with few historical survey data available for direct comparison, we restricted our analyses to species diversity at the scale of interest, versus any interpretation of spatio-temporal changes to community structure and abundance, which is beyond the scope of this article.

\section{Discussion}

Formal historical records accounting for species loss in the Simalaha and Nyawa areas are unavailable, although local Traditional Authorities (HRH Chief Inyambo Yeta \& HRH Chief Moomba, pers. comms 2015) emphasized the impact of the Angolan Bush War (1966-1989) as a key driver, describing encampments of foreign combatants in Simalaha being used as a base to exploit the area's wildlife for rations and profit. Following the cessation of hostilities there was a proliferation of small firearms in the area, and in conjunction with an increasing human population and limited funding for law enforcement and natural resource management, unsustainable harvesting of wildlife continued. Given these circumstances we hypothesize that wildlife 


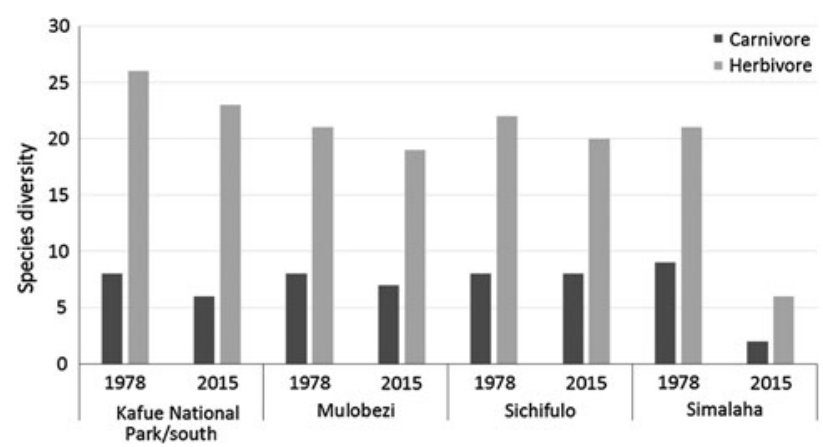

FIG. 5 Changes in carnivore and herbivore diversity in wildlife management areas at the Kafue-Zambezi interface (Fig. 1) during 1978-2015.

management areas closer to Kafue National Park were spared much of this pressure, having also received more political and revenue support for wildlife management in the long term (L. Daka, pers. comm. 2015).

Surveys at the Kafue-Zambezi interface have employed a range of ad hoc methodological approaches that failed to detect the majority of resident species throughout this landscape. The absence of a reliable baseline undermines efforts to evaluate the effectiveness of large-scale conservation interventions required to deliver key programme objectives within and between clusters of wildlife management areas.

Acknowledging non-detection error, we confirm that the diversity of terrestrial mammals $(>10 \mathrm{~kg}$ ) in southern Kafue National Park remains unchanged since 1978. Mulobezi and Sichifulo retain largely intact mammalian diversity, with the notable exception of the hippopotamus. No new data could be provided for the presence of free-ranging giraffes in any of these wildlife management areas.

A single-season survey design increases non-detection error associated with species dispersal or seasonal wildlife movement patterns; nonetheless, widespread losses, including three of six carnivore species and 16 of 25 prey species, were detected in the Simalaha Communal Conservancy/ Nyawa areas, which link wildlife management areas at the interface of the Greater Kafue System and adjacent wildlife management areas in Namibia and Botswana.

These data emphasize the challenges associated with the scope and scale of conservation interventions required to limit factors driving species loss from seven of nine taxonomic families, representing a wide range of species traits. If drivers of species loss continue to limit population recovery in the Simalaha/Nyawa areas then source-sink dynamics and edge effects can have a negative impact on the population viability of vulnerable species in peripheral wildlife management areas at local and transboundary scales.

Wide-ranging species are particularly susceptible to source-sink dynamics and edge effects, and therefore the absence of large carnivores from the Simalaha and the Simalaha Wildlife Recovery Sanctuary indicates the need for additional research to understand the status and drivers

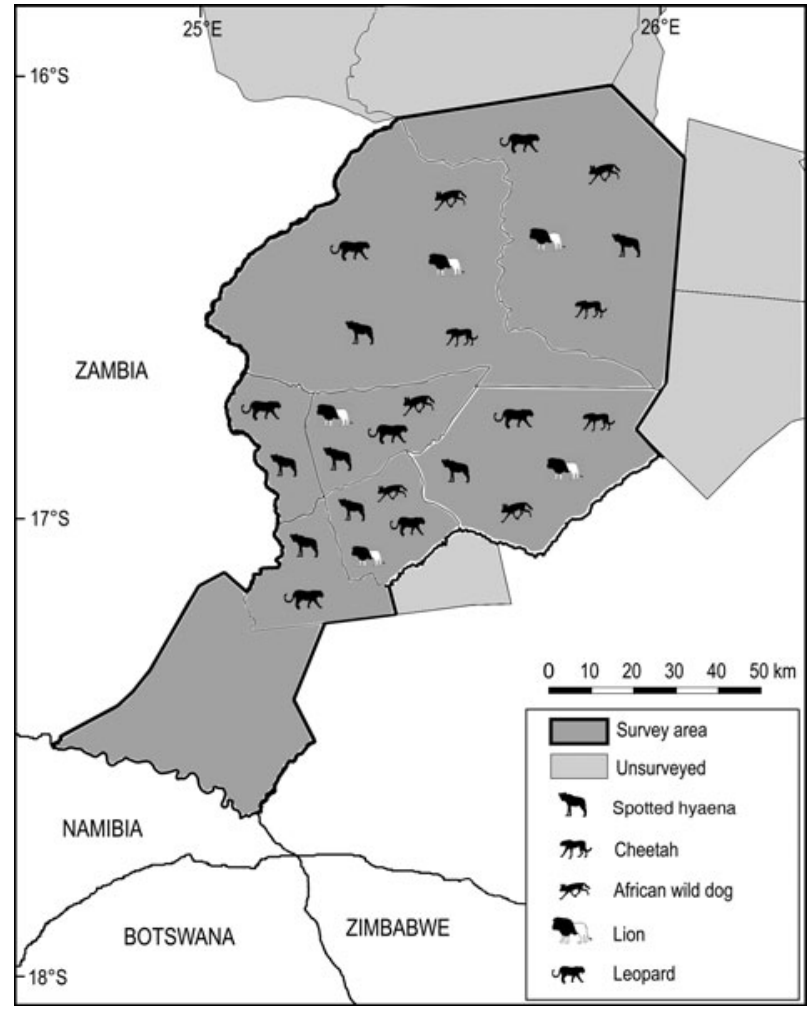

FIG. 6 Distribution of the spotted hyaena Crocuta crocuta, cheetah Acinonyx jubatus, African wild dog Lycaon pictus, lion Panthera leo and leopard Panthera pardus at the Kafue-Zambezi interface (Fig. 1) in 2014-2015.

of wildlife occurrence and distribution south of the Zambezi River throughout the wildlife management areas of the eastern Zambezi region in Namibia, and the potential effects of ecological traps/attractive sinks at transboundary scales on wildlife management interventions in Simalaha and other neighbouring wildlife management areas of Zambia.

Broader scale implications of species loss and ecological traps within the Kavango-Zambezi Transfrontier Conservation Area relate to dominant narratives about the connectivity of wildlife management areas. The extent to which existing and emerging drivers of species loss are severing biological linkages between the Greater Kafue System and adjacent wildlife management areas remain unquantified and subject to speculation. However, data suggest there is a connectivity bottleneck for large mammals in the Simalaha Communal Conservancy, with only 10 of 31 species known from historical records detected throughout this area in 2014-2015.

The long-distance dispersal capabilities of large carnivores imply scope for gene flow between the Greater Kafue System and adjacent wildlife management areas in the Kavango-Zambezi Transfrontier Conservation Area, and therefore the extent to which connectivity bottlenecks impact processes of immigration and emigration in highly mobile species is a priority area of research for regional connectivity conservation management. 
We focused on ascertaining changes to the occurrence and distribution of 38 terrestrial mammals $>10 \mathrm{~kg}$ known from four composite wildlife management areas between the Greater Kafue System and a central cluster of wildlife management areas in the Kavango-Zambezi Transfrontier Conservation Area, and the methodological approach was successful for 31 species at the scale of interest. These data cannot elucidate population numbers and trends, but it is apparent that ongoing attempts to maintain population viability of vulnerable species and wildlife connectivity between clusters of wildlife management areas, and the promotion of wildlifebased land uses, will depend on diagnosing and treating the interacting ecological, socio-economic and political drivers of species loss within and between clusters of wildlife management areas, utilizing comparative studies at appropriate temporal and spatial scales. The limits to which sufficient political and economic capital can be leveraged to bridge these knowledge gaps, act accordingly on the findings, and implement monitoring, evaluation and feedback are likely to determine future connectivity for Zambia's majority component within the Kavango-Zambezi Transfrontier Conservation Area.

\section{Acknowledgements}

We thank A. Nambota for assistance with study development; D. MacKenzie and P. Henschel for assistance with study design; P. Moss, J. Hanks and M. Musgrave for insights into Kafue National Park and surrounding Game Management Areas; the Chilanga, Ngoma, Mulobezi and Mulanga offices of the Department of Parks and Wildlife Management (formerly the Zambia Wildlife Authority) for permissions and field support; P. Matape, M. Samuntafu, E. Kashaye, D. Mundia, G. Kambole and R. Kraljic for field support; and HRH Chief Inyambo Yeta of the Lozi and the late HRH Chief Moomba of the Nkoya, for granting smooth passage through their Chiefdoms. Funding was provided by Humane Society Australia, WWF Namibia, MergerMarket Group and Westwood, with grant management through TUSK Trust UK and the Namibia Nature Foundation. RL's PhD is supported by a University of Kent at Canterbury 5oth Anniversary Graduate Teaching Scholarship.

\section{Author contributions}

RL designed and undertook fieldwork and wrote the article, with input from JT and DM on structure and analysis.

\section{References}

Andersson, J., De Garine-Wichatitsky, M., Cumming, D., Dzingirai, V. \& Giller, K. (eds) (2017) Transfrontier Conservation Areas: People Living on the Edge. Routledge, Abingdon, UK.
AnselL, W.F.H. (1957) Some mammals from Northern Rhodesia. Journal of Natural History, 10, 529-551.

Ansell, W.F.H. (1959) Further data on Northern Rhodesian ungulates. Mammalia, 23, 332-349.

Ansell, W.F.H. (1960) Mammals of Northern Rhodesia. The Government Printer, Lusaka, Northern Rhodesia.

Ansell, W.F.H. (1978) The Mammals of Zambia. National Parks \& Wildlife Service. The Government Printer, Lusaka, Zambia.

B AtTin, J. (2004) When good animals love bad habitats: ecological traps and the conservation of animal populations. Conservation Biology, 18, 1482-1491.

Bellard, C., Bertelsmeier, C., Leadley, P., Thuiller, W. \& Courchamp, F. (2012) Impacts of climate change on the future of biodiversity. Ecology Letters, 15, 365-377.

Biggs, R., Simons, H., Bakkenes, M., Scholes, R.J., Eickhout, B., van VuUren, D. \& Alkemade, R. (2008) Scenarios of biodiversity loss in southern Africa in the 21st century. Global Environmental Change, 18, 296-309.

Brelsford, W.V. (1965) The Tribes of Zambia. The Government Printer, Lusaka, Zambia.

Cardillo, M., Mace, G.M., Gittleman, J.L., Jones, K.E., Bielby, J. \& Purvis, A. (2008) The predictability of extinction: biological and external correlates of decline in mammals. Proceedings of the Royal Society B: Biological Sciences, 275, 1441-1448.

CSO (Central Statistics Office of Zambia) (2010) Http://www. zamstats.gov.zm/ [accessed 23 June 2014].

Cumming, D.H.M. (2008) Large Scale Conservation Planning and Priorities for the Kavango-Zambezi Transfrontier Conservation Area. A report for Conservation International, Arlington, USA.

Cumming, G.S. (2011) Spatial Resilience in Social-ecological Systems. Springer Science \& Business Media, Dordrecht, Netherlands.

DNPW (Department of National Parks and Wildlife) (2016) Report on the 2015 Aerial Census of Elephants and Other Large Mammals in Zambia: Volume II, Population Estimates for Other Large Mammals and Birds. Department of National Parks and Wildlife, Chilanga, Zambia.

Fischer, J., Lindenmayer, D.B. \& Manning, A.D. (2006) Biodiversity, ecosystem function, and resilience: ten guiding principles for commodity production landscapes. Frontiers in Ecology and the Environment, 4, 80-86.

Funston, P.J., Frank, L., Stephens, T., Davidson, Z., Loveridge, A., Macdonald, D.M. et al. (2010) Substrate and species constraints on the use of track incidences to estimate African large carnivore abundance. Journal of Zoology, 281, 56-65.

Hanks, J. (2000) The role of Transfrontier Conservation Areas in southern Africa in the conservation of mammalian biodiversity. In Priorities for the Conservation of Mammalian Diversity. Has the Panda had its Day? (eds A. Entwistle \& N. Dunstone), pp. 239-256. Cambridge University Press, Cambridge, UK.

HANKS, J. (2003) Transfrontier Conservation Areas (TFCAs) in southern Africa: their role in conserving biodiversity, socioeconomic development and promoting a culture of peace. Journal of Sustainable Forestry, 17, 127-148.

HANKS, J. \& MYBURGH, W. (2015) The evolution and progression of Transfrontier Conservation Areas in the southern African development community. In Institutional Arrangements for Conservation, Development and Tourism in Eastern and Southern Africa (eds R. van der Duim, M. Lamers \& J. van Wijk), pp. 157-179. Springer, Dordrecht, Netherlands.

Holub, E. (1975) Emil Holub's Travels North of the Zambezi, 1885-6. Manchester University Press, Manchester, UK.

JACHMAnN, H. (2002) Comparison of aerial counts with ground counts for large African herbivores. Journal of Applied Ecology, 39, 841-852. 
KAZA TFCA Secretariat (2011a) Treaty Between the Governments of Angola, Botswana, Namibia, Zambia and Zimbabwe on the Establishment of the Kavango-Zambezi Transfrontier Conservation Area. Kavango-Zambezi TFCA Secretariat, Kasane, Botswana.

KAZA TFCA Secretariat (2011b) Strategic Action Plan. KavangoZambezi TFCA Secretariat, Kasane, Botswana.

KAZA TFCA Secretariat (2014) Master Integrated Development Plan. Kavango-Zambezi TFCA Secretariat, Victoria Falls, Zambia.

LanCaster, D.G. (1953) A Check List of the Mammals of Northern Rhodesia. The Government Printer, Lusaka, Northern Rhodesia.

Lindsey, P., Balme, G., Becker, M., BegG, C., Bento, C., Bocchino, C. et al. (2013a) Illegal hunting and the bush-meat trade in savanna Africa: drivers, impacts and solutions to address the problem. FAO, Panthera/Zoological Society of London/Wildlife Conservation Society report, New York, USA.

Lindsey, P.A., Havemann, C.P., Lines, R.M., Price, A.E., Retief, T. A., Rhebergen, T. et al. (2013b) Benefits of wildlife-based land uses on private lands in Namibia and limitations affecting their development. Oryx, 47, 41-53.

MacKenzie, D.I. \& Royle, J.A. (2005) Designing occupancy studies: general advice and allocating survey effort. Journal of Applied Ecology, 42, 1105-1114.

Margules, C.R. \& Pressey, R.L. (2000) Systematic conservation planning. Nature, 405, 243-253.

Maxwell, S.L., Fuller, R.A., Brooks, T.M. \& Watson, J.E.M. (2016) Biodiversity: the ravages of guns, nets and bulldozers. Nature, $536,143-145$.

Millennium Ecosystem Assessment (2005) Ecosystems and Human Well-being: Synthesis. Island Press, Washington, DC, USA.

Moss, P. (2012) Handbook to Kafue National Park. Future Publishing (PTY) Ltd., Johannesburg, South Africa.

Musgrave, M. (2016) Scale, Governance and Change in Zambezi Teak Forests: Sustainable Development for Commodity and Community. Cambridge Scholars Publishing, Newcastle upon Tyne, UK.

NeWmark, W.D. (2008) Isolation of African protected areas. Frontiers in Ecology and the Environment, 6, 321-328.

Ogutu, J.O., Piepho, H.P., Said, M.Y., Ojwang, G.O., Nino, L.W., Kifugo, S.C. \& Wargute, P.W. (2016) Extreme wildlife declines and concurrent increase in livestock numbers in Kenya: what are the causes? PLOS ONE, 11(9), e0163249.

Pachauri, R.K., Allen, M.R., Barros, V.R., Broome, J., Cramer, W., Christ, R. et al. (2014) Climate Change 2014: Synthesis Report. Contribution of Working Groups I, II and III to the Fifth Assessment Report of the Intergovernmental Panel on Climate Change. Intergovernmental Panel on Climate Change, Geneva, Switzerland.

Pitman, C. (1934) A Report on a Faunal Survey of Northern Rhodesia. Government Printer, Livingstone, Northern Rhodesia.

PPF (Peace Parks Foundation) (2008) Integrated Development Plan for the Zambian Component of the Kavango-Zambezi Transfrontier Conservation Area. Peace Parks Foundation, Stellenbosch, South Africa.

PPF (Peace Parks Foundation) (2015) Restocking Simalaha Community Conservancy. Http://www.peaceparks.org/news.php? pid $=1481 \&$ mid $=1546 \&$ lid $=1120$ [accessed 17 July 2017].
QGiS Development Team (2016) Quantum GIS Geographic Information System. Open Source Geospatial Foundation Project. Https://www.osgeo.org/projects/qgis/.

SAMPSOn, R. (1972) The Man with a Toothbrush in His Hat: The Story and Times of George Copp Westbeech in Central Africa. Multimedia Publications, Lusaka, Zambia.

Simukonda, C. (2008) A Countrywide Survey of Large Mammals, Zambia. Zambia Wildlife Authority, Lusaka, Zambia.

Sutherland, W.J., Pullin, A.S., Dolman, P.M. \& Knight, T.M. (2004) The need for evidence-based conservation. Trends in Ecology \& Evolution, 19, 305-308.

Thorn, M., Green, M., Bateman, P.W., Cameron, E.Z., Yarnell, R.W. \& SсотT, D.M. (2010) Comparative efficacy of sign surveys, spotlighting and audio playbacks in a landscape-scale carnivore survey. South African Journal of Wildlife Research, 40, 77-86.

UNEP-WCMC (United Nations Environment Programme World Conservation Monitoring Centre) (2016). Protected Planet Database. Http://www.protectedplanet.net [accessed 1 May 2015].

United Nations, Department of Economic and Social Affairs, Population Division (2015) World Population Prospects: The 2015 Revision. Key Findings and Advance Tables. Working Paper No. ESA/P/WP.241.

van der Linde, H., Oglethorpe, J., Sandwith, T., Snelson, D., Tessema, Y., Tiéga, A. \& Price, T. (2001) Beyond Boundaries: Transboundary Natural Resource Management in Sub-Saharan Africa. Biodiversity Support Program, Washington, DC, USA.

Watson, F.G.R., Becker, M.S., Milanzi, J. \& Nyirenda, M. (2015) Human encroachment into protected area networks in Zambia: implications for large carnivore conservation. Regional Environmental Change, 15, 415-429.

Woodroffe, R. \& Ginsberg, J.R. (1998) Edge effects and the extinction of populations inside protected areas. Science, 280, 2126-2128.

WWF (2011) A brighter future for communities and wildlife. Http:// www.worldwildlife.org/stories/a-brighter-future-for-communitiesand-wildlife [accessed 15 February 2016].

ZAWA (Zambia Wildlife Authority) (2010) General Management Plan for Kafue National Park. ZAWA, Chilanga, Zambia.

ZвісZ, D. (1999) Transboundary cooperation between internationally adjoining protected areas. In On the Frontiers of Conservation: Proceedings of the 1oth Conference on Research and Resource Management in Parks and on Public Lands. The George Wright Society, Hancock, USA.

\section{Biographical sketches}

Roв IN LINES is a conservation biologist working on large carnivore conservation, human-wildlife interactions, community conservation and the promotion of wildlife-based land uses. JOSEPH TZANOPOULOS is interested in geographical information systems, nature conservation policy and governance, and impact assessment of land-use changes. Douglas MacMillan is interested in the economics of wildlife conservation, wildlife trade and poaching, human-wildlife interactions, and land-use change. 